\title{
STUDY OF ON-DEMAND SHARED RIDE-HAILING COMMUTING SERVICE: FIRST RESULTS FROM A CASE STUDY IN BARCELONA
}

\author{
MIREIA GILIBERT ${ }^{1,2}$, IMMA RIBAS $^{1}$ \& SILVIA RODRIGUEZ-DONAIRE ${ }^{1}$ \\ ${ }^{1}$ Departament d'Organització d'Empreses (DOE), Universitat Politècnica \\ de Catalunya BarcelonaTech (UPC), Spain \\ ${ }^{2}$ SEAT, S.A., Autovía A-2, Spain
}

\begin{abstract}
Shared ride-hailing services are discreetly emerging in cities all over the world, with the purpose of providing a transport service more flexible than the public bus and cheaper than the regular taxi. Hence, it is important to identify and include the relevant and key factors of such a service to ensure its success. The aim of this study was to investigate the utility of an on-demand shared ride-hailing commuting service and determine the design factors for an appropriate service from the users' perspective. For one week, a pilot of a shared ride-hailing services to commute from the city centre of Barcelona to the most western district of the city was conducted. Although the sample used in this study was modest in scale, it enabled to draw preliminary conclusions. Users valued very positively the comfort provided but they would not pay more than the double of the price of the public transport. This indicates that despite having a high number of users, such a low price could complicate the profitability of the service unless it was partially subsidized.

Keywords: Mobility as a Service (MaaS), ride-hailing, ridesharing, ride-sourcing, urban mobility, ondemand transport, Business Model Canvas.
\end{abstract}

\section{INTRODUCTION}

Urban mobility is a current trending topic, since cities, on one hand, are facing the rising problem of urbanization and, on the other, the growth of urban traffic and the rise of environmental and health problems as a consequence of urbanization. To address the issue of urban traffic and its associated problems, driving restrictions are being more common in big cities. But what does sustainable mobility mean? Is it e-mobility, shared mobility or both? In the last years, there has been a growth of on-demand shared transport initiatives, such as Zipcar and car2go, which enable renting a car by hours or minutes (carsharing), or Uber and BlaBlaCar, which enable sharing a ride in a taxi or in a private vehicle (ride-hailing and ridesharing). These new players detected new business opportunities in this sector, emerged and are expanding their services all over the world.

In this study, we focus on shared ride-hailing. This emerging model, which covers the gap between the bus and the taxi, could be a good complement to the existing cities' mobility offer and a more sustainable and adequate way to commute within the city. Ride-hailing services are growing as an alternative to the taxi, offering flexible and low cost on-demand rides in an easy way and a better user experience [1]-[4]. Drivers are either freelance or employed, therefore, have an economical return for their jobs; and their reservation is ondemand. A recent study based in New York City concluded that the $98 \%$ of the taxi demand could be covered using 2,000 vehicles with capacity for 10 people or 3,000 with capacity for 4 people, which is, respectively, the $15 \%$ and the $22 \%$ of the current taxi fleet [5]. Besides, some public transport operators are beginning to transform their bus services, based on this on-demand concept, to make the public transport more efficient and suitable to commute. For instance, this is the case of the Oxford bus company, which is beginning a demand-responsive bus service to improve the public transport offer in the Eastern Arc around Oxford [6]. 
The case study developed was based in Barcelona, which is a top Smart City according to Juniper Research's ranking [7], [8] and where right now measures for improving the sustainability have been announced, such as the restriction of most polluting vehicles travelling within the city during the days with high air pollution and their total restriction from 2020 onwards [9].

Within Barcelona, the $49.4 \%$ of commuting trips are done by private cars and motorbikes, the $29.6 \%$ by public transport and the remaining $21 \%$ by non-motorised means [10]. Besides, on a working day, more than one million vehicles enter and leave Barcelona [11]. Another study found out that more than a quarter of commuters to or from Barcelona not using the public transport was due to not having this type of offer at all to cover their trips or with too few services per day [12]. This research also pointed out that more than a half of the commuters used more than one mode of transport to reach their destinations and a quarter of them combined both the public transport and the private car for a better efficiency in terms of money and time.

Since the public transport cannot always satisfy all the needs of travellers, there is an opportunity for shared mobility services to reach the areas inefficiently or still not covered by the public transport, as well as to better cover the needs of multimodal commuters. Hence, our research question is whether shared ride-hailing services would be suitable for commuting and which key factors should be taken into account in the service design.

\section{METHODOLOGY}

The methodology used to conduct this study was first, a review of literature regarding business models applied to shared ride-hailing. Then, an action research consisting on interviewing users and collaborators of these services as well as an analysis of websites of other representative services was conducted. The information obtained was analysed using the methodology of Business Model Canvas (BMC), which provides a clear overview of the business functions. Finally, to verify the utility of the commuting shared ride-hailing business model, a pilot service was operated during one week in Barcelona.

\section{RESULTS}

\subsection{Shared ride-hailing business model}

From among all new mobility services, shared ride-hailing is the least common to find. However, the American Peer-to-Peer (P2P) services UberPOOL and Lyft Line cover many American cities [13], [14], whereas the Chinese P2P operator DiDi covers many Chinese cities, among others [15]. Business-to-Consumer (B2C) services are not yet so widespread. For instance, the American Via offers its mobility service in three US cities: Chicago, New York and Washington DC [16]; the American Chariot covers 6 American cities and London [17]; and the German MOIA is testing its service in Hannover and plans to launch the service in Hamburg at the end of 2018 [18]. Based on the analysis of the literature review and the information obtained in the action research, by means of the BMC, we found that shared ridehailing would be a recommended service for regular urban uses. We identified that, in most cases, the customer segment targeted is urban commuters. For instance, Via accepts payments from commuter benefits debit cards [16]. Besides, Watanabe et al. [19] remarked that Uber, in countries like Saudi Arabia, offers a reliable transport for women which enables them to keep their jobs. The value proposition of shared ride-hailing is to offer flexible and low-cost on-demand rides [1]-[4]. The main channels used to reach customers are the user app and the website, and the customer relationships are usually managed by an app-based reputation 
system and the customer service [20]. Regarding the revenue streams, this type of transportation is offered through pay per use, but with different combinations depending on the operator. This way, whereas UberPOOL charges a rate per mile and minute plus the surge pricing [13], Via offers a fixed price for the whole area covered [16]. On the other hand, P2P services such as UberPOOL or Lyft Line charge a commission per trip to their drivers. The main key resources are the vehicles (owned by the operator or by the freelance drivers), skilled drivers, the application for the user to request the rides and the driver to accept the rides and see the route to follow, and the routing and matching algorithms, which enable the service to be shared by different users travelling to the same direction. Besides, the main key activities are the development of the technological platform, the fleet operation and management and the maintenance of the vehicles. As key partnerships, the service requires providers of ICT platforms, digital payment, geolocalization and insurances [2], [4], as well as the authorization to operate of the local governments and, in the P2P model, freelance drivers. The main costs of the cost structure are the personnel, the acquisition and maintenance of the vehicles and the development of the apps, algorithms and platforms required. Table 1 summarizes the key features of each building block of the shared ridehailing business model.

\subsection{Case study}

A first pilot of the shared ride-hailing commuting service was done in Barcelona with a participation of 55 users, with the aim of identifying the most valued service factors from the

Table 1: Summary of the main characteristics of shared ride-hailing.

\begin{tabular}{|l|l|}
\hline Business model block & Shared ride-hailing \\
\hline Customer segments & Urban regular users \\
\hline Value proposition & On-demand rides \\
\hline Channels & Application and website \\
\hline Customer relationships & $\begin{array}{l}\text { Reputation system } \\
\text { Customer service }\end{array}$ \\
\hline Revenue streams & $\begin{array}{l}\text { Pay per use } \\
\text { Commission per ride (P2P model) }\end{array}$ \\
\hline \multirow{5}{*}{ Key resources } & $\begin{array}{l}\text { Vehicles } \\
\text { Skilled drivers } \\
\text { User and driver apps } \\
\text { Routing and matching algorithms }\end{array}$ \\
\hline \multirow{5}{*}{ Key partnerships } & $\begin{array}{l}\text { Development of the tech platform } \\
\text { Operate and manage the fleet } \\
\text { Vehicle maintenance }\end{array}$ \\
\hline \multirow{2}{*}{ Cost structure } & $\begin{array}{l}\text { Local governments } \\
\text { Providers of ICT platforms, digital } \\
\text { payment, geolocalization, insurance } \\
\text { Freelance drivers (P2P) }\end{array}$ \\
\hline & $\begin{array}{l}\text { Personnel costs } \\
\text { Fleet acquisition and maintenance } \\
\text { Software development }\end{array}$ \\
\hline
\end{tabular}


users' perspective and, moreover, to verify the suitability of it for the use case studied: commuting within the city. The test took place in April 2017 and lasted one week. The users used to commute every day from the city centre of Barcelona (Eixample district) to the most western district of the city (Les Corts). Previous to the test, they downloaded the application for the on-demand pick-up requests. To gather some results about the experience, a quantitative study was conducted using a Likert scale questionnaire. The sample profile obtained was:

- Gender: $58.2 \%$ men and $41.8 \%$ women

- Age: $49.1 \%$ aged between 18 and 29 years old, $36.4 \%$ aged between 30 and 45 years old, $12.7 \%$ aged between 46 and 55 years old, and the remaining $1.8 \%$ aged more than 55 years old

- Occupation: $72.7 \%$ were employed, $7.3 \%$ were students which also were working, and the remaining $20 \%$ were students exclusively dedicated to their studies

- Have a driving license: $85.5 \%$

- Access or owners of a car: $51 \%$

- Access or owners of a motorbike: $27.3 \%$

- Means of transport used (multiple responses): see Fig. 1

The questionnaire applied was structured with closed questions. Interviewees expressed their opinion on a 7-likert scale (Table 2).

The users of the test service valued better the comfort and the punctuality of the shuttle service provided better than the provided by the regular bus and taxi service. The speed and

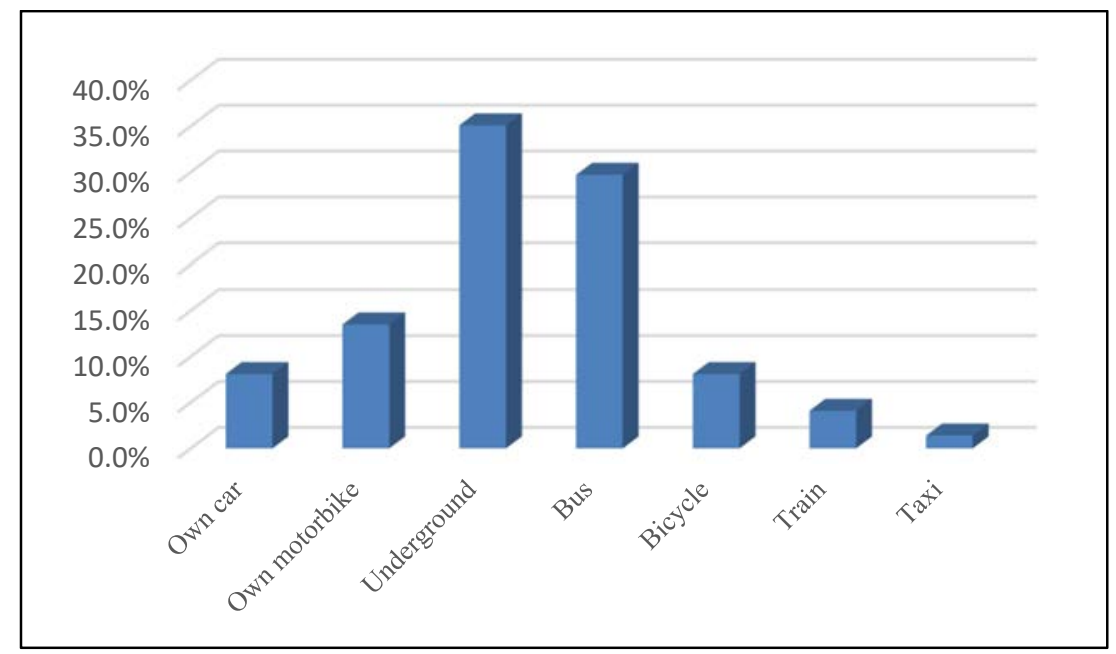

Figure 1: Commuting mean of transport of the participants.

Table 2: Rating scale.

\begin{tabular}{|c|c|c|c|c|c|c|}
\hline $\begin{array}{c}\text { Totally } \\
\text { disagree }\end{array}$ & $\begin{array}{c}\text { Strongly } \\
\text { disagree }\end{array}$ & Disagree & $\begin{array}{c}\text { Neither agree } \\
\text { or disagree }\end{array}$ & Agree & $\begin{array}{c}\text { Strongly } \\
\text { agree }\end{array}$ & $\begin{array}{c}\text { Totally } \\
\text { agree }\end{array}$ \\
\hline 1 & 2 & 3 & 4 & 5 & 6 & 7 \\
\hline
\end{tabular}




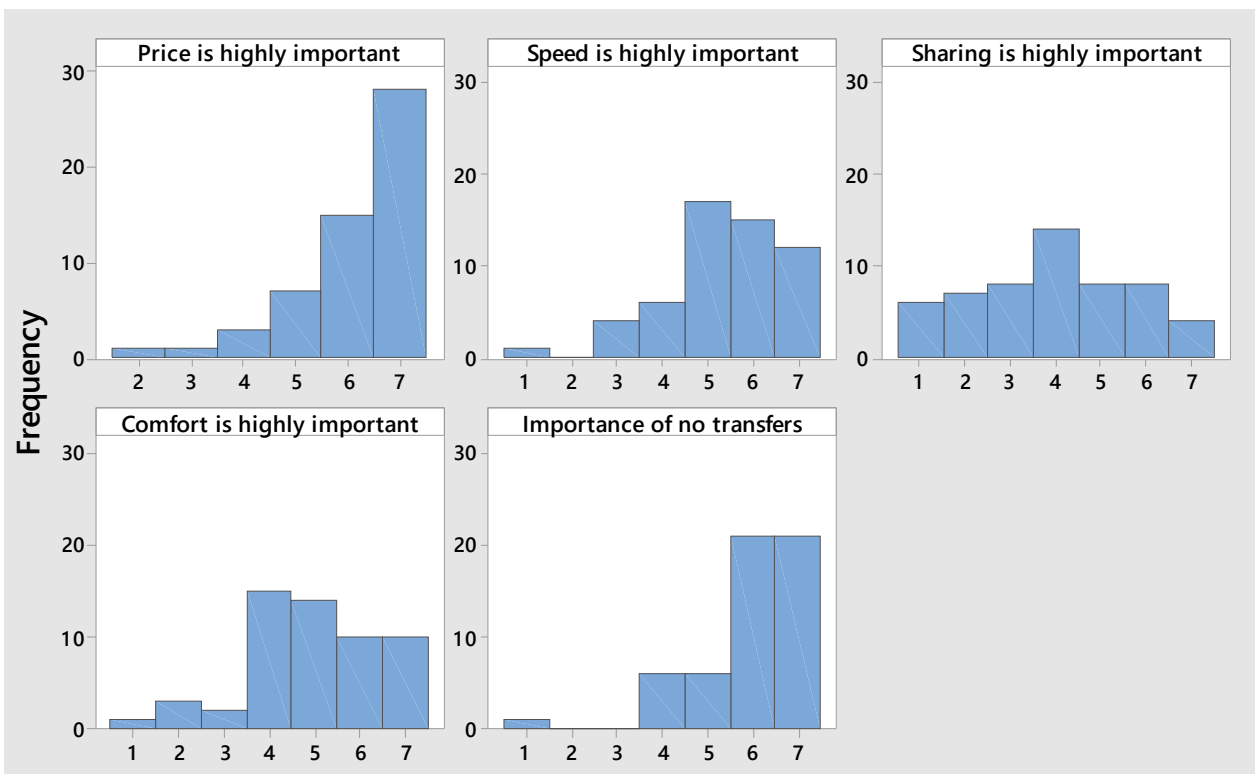

Figure 2: Histogram of the importance of price, speed, sharing, comfort and no transfers.

the waiting time were also better than the bus, from the users' point of view, but worse than the taxi service.

We found that in order to become a regular user of a shared ride-hailing service, the price is the most important factor, followed by the fact of not having transfers, the speed of the trip and the comfort (Fig. 2). The fact of sharing the ride in order to meet new people was not so important for the participants.

Participants would accept paying a little more than the price of the public transport, but less than the double. Concerning the price calculation, participants voted in favor of having a flat rate to travel within the city (38.9\%). Establishing the price according to the distance of the straightest path or to the travel time on the fastest way was preferred by the $33.3 \%$ and the $27.8 \%$ respectively. In addition, the $72.7 \%$ of participants specified that their use would be higher if there was a loyalty card, and the $81.8 \%$ would increase their use if the payment method was the same as the public transportation. On the other hand, $85.5 \%$ of participants would accept walking up to 5 minutes to the pick-up point but only $27.3 \%$ would accept that the pick-up point was in a 10 minutes walking distance. Besides, the $51 \%$ of participants would be willing to wait up to 10 minutes for being picked up.

Asked about the importance of the service factors, as shown in Fig. 3, they highlighted the requirements of the service to be available, reliable, safe and clean.

\section{CONCLUSION}

Given the rising trend of cities establishing policies to reduce the number of private vehicles from their streets, and considering that a large proportion of them are used to commute on a daily basis, this study aimed to analyse if shared ride-hailing could be an alternative to private cars to commute as well as to find out the design factors to take into account in the design of the business model. 


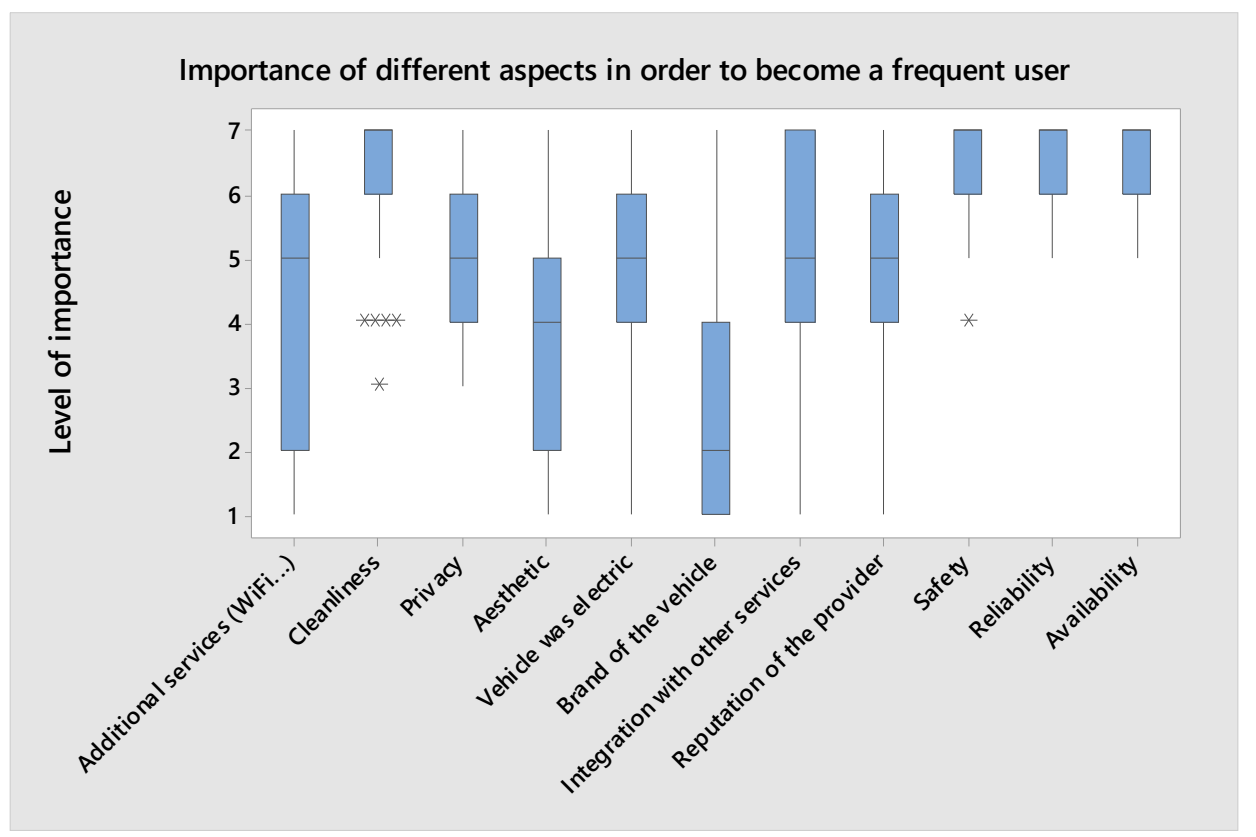

Figure 3: Boxplot of the importance of service factors to become a frequent user of the service.

First, from the literature review and the action research, the main characteristics of the shared ride-hailing business model were analysed and summarized. Then, a pilot service was conducted to determine the service factors that best suit the use case of commuting. In terms of the BMC, the case study suggested that the value proposition of the service should include the requirements of availability, reliability, safety and cleanness, and proved the importance of the price in order to become a regular user, which has a direct effect on the revenue streams.

This study confirmed that shared ride-sourcing could be an alternative to private cars to commute, especially for the trips that made by public transport require transfers, since the fact of having a direct service was the second factor most valued by the users. Furthermore, many commuters use first the private car due to not having a suitable public transport option and travel the last mile with the public transport to avoid the traffic or paying for parking. Therefore, this type of service could help commuters to save time and money.

However, the price per trip will be a determining factor for the success of the service, since the users would not pay more than the double of the price of the bus or the subway. Considering that such a low price could complicate the profitability of the service, partnerships with the administrations or with other third parties in order to subsidize the service could be essential. Besides, the mobility service should also cover other use cases targeting other customer segments on top of the specific commuting use case to be as costeffective as possible.

\section{ACKNOWLEDGMENT}

This study was supported by SEAT, S.A., CARNET and Generalitat de Catalunya (AGAUR) [2016 DI 023]. 


\section{REFERENCES}

[1] Bonazzi, R. \& Pigneur, Y., The Hitchhiker's Guide to the Galaxy of Dynamic Ridesharing. pp. 1207-1216, 2015.

[2] Gao, S. \& Zhang, X., Understanding Business Models in the Sharing Economy in China: A Case Study in Social Media. The Good, the Bad, and the Ugly, eds. Y.K. Dwivedi, et al., Springer International Publishing: Cham, vol. 9844, pp. 661-672, 2016.

[3] Watanabe, C., Naveed, K. \& Neittaanmäki, P., Co-evolution of three mega-trends nurtures un-captured GDP-Uber's ride-sharing revolution. Technology in Society, 46, pp. 164-185, 2016. DOI: 10.1016/j.techsoc.2016.06.004.

[4] Janasz, T. \& Schneidewind, U., The Future of Automobility. Shaping the Digital Enterprise, eds G. Oswald \& M. Kleinemeier, Springer International Publishing: Cham, pp. 253-285, 2017.

[5] Alonso-Mora, J., Samaranayake, S., Wallar, A., Frazzoli, E. \& Rus, D., On-demand high-capacity ride-sharing via dynamic trip-vehicle assignment. Proceedings of the National Academy of Sciences, 114(3), pp. 462-467, 2017.

DOI: $10.1073 /$ pnas. 1611675114 .

[6] Oxford Mail, "Uber for buses" could pick you up anywhere in east of Oxford in under 10 minutes', Oxford Mail, 11-May-2018. Online.

www.oxfordmail.co.uk/news/16219236.New__Uber_for_buses__could_pick_y ou_up_from_home_in_under_10_minutes/. Accessed on: 20 May $\overline{2018}$.

[7] Juniper Research, Barcelona Named "Global Smart City - 2015", Juniper Research, 2015. Online. www.juniperresearch.com/press/press-releases/barcelona-namedglobal-smart-city. Accessed on: 17 Feb. 2017.

[8] Juniper Research, Singapore Named "Global Smart City-2016", Juniper Research, 2016. Online. www.juniperresearch.com/press/press-releases/singapore-namedglobal-smart-city. Accessed on: 17 Feb.2017.

[9] Guerrero, D., Barcelona restringirá la circulación de los vehículos más contaminantes de forma permanente a partir de 2020, La Vanguardia, 21-Nov-2016. Online. www.lavanguardia.com/local/barcelona/20161121/412028354146/barcelonarestricciones-coches-mas-contaminantes-2020.html. Accessed on: 9 Mar. 2017.

[10] Barcelona Institute of Regional and Metropolitan Studies, Workday Mobility Survey in the RMB, 2015, 2016.

[11] Barcelona City Council, Traffic volume at the entrances to the city. 2011-2015, Statistical Yearbook of Barcelona City. Year 2016, 2016. Online. www.bcn.cat/estadistica/angles/dades/anuari/cap15/C1511010.htm. Accessed on: 8 Aug. 2017.

[12] Gilibert, M., Ribas, I. \& Rodriguez-Donaire, S., Analysis of mobility patterns and intended use of shared mobility services in the Barcelona region. Presented at The European Transport Conference 2017, Barcelona, 2017.

[13] Uber, 2017. Online. www.uber.com/es-ES/. Accessed on: 25 Jan. 2017.

[14] 'Lyft Line', Lyft, 2018. Online. www.lyft.com/line. Accessed on: 20 May 2018.

[15] 'Didi Chuxing', Didi Chuxing, 2018. Online. www.didichuxing.com/en/. Accessed on: 20 May 2018.

[16] 'Via', Via, 2018. Online. https://ridewithvia.com/. Accessed on: 20 May 2018.

[17] 'Chariot', Chariot, 2018. Online. www.chariot.com/. Accessed on: 20 May 2018.

[18] MOIA startet Ridepooling-Test in Hannover, Volkswagen AG, 2018. Online. www.volkswagenag.com/de/news/stories/2017/10/moia-launches-ride-pooling-testin-hanover.html\#. Accessed on: 20 May 2018. 
[19] Watanabe, C., Naveed, K., Neittaanmäki, P. \& Fox, B., Consolidated challenge to social demand for resilient platforms-Lessons from Uber's global expansion. Technology in Society, 48, pp. 33-53, 2017. DOI: 10.1016/j.techsoc.2016.10.006.

[20] Wu, L., Understanding collaborative consumption business model: case of car sharing systems. Presented at The International Conference on Materials, Manufacturing and Mechanical Engineering (MMME 2016), Beijing, 2016, vol. DEStech, pp. 403-409. 